one patient with tricuspid incompetence due to a ruptured papillary muscle after myocardial infarction. The higher incidence of left ventricular papillary muscle dysfunction reported (Heikkilä, 1967) must be largely due to the higher incidence of left ventricular infarction observed by various workers (Wartman \& Hellerstein, 1948; Zaus \& Kearns, 1952).

This patient had minimal dilatation of the tricuspid valve ring and the valves at post-mortem appeared competent. The neropsy impression is occasionally misleading as the valve ring may be larger during life, when the pressure in the right ventricle is increased. However, in this patient tricuspid incompetence persisted, although the clinical signs of heart failure were mild, although such failure as was present improved with treatment, and despite a decrease in heart size on the chest X-ray. This clinical course in conjunction with the autopsy findings make papillary muscle dysfunction the only tenable explanation for this patient's tricuspid incompetence.

The mechanism of papillary muscle dysfunction in the left ventricle was reviewed by Burch, De Pasquale \& Phillips (1963) and more recently by Raftery, Oakley \& Goodwin (1966). The very prominent ' $v$ ' waves and ' $y$ ' descent in the jugular veins of this patient accord well with the left atrial pressure tracings found in patients with left ventricular papillary muscle dysfunction (Raftery et al., 1966). The right atrium in this patient was presumably normal before the sudden development of tricuspid incompetence and the venous pressure excursions were not damped because the atrium was still relatively uncompliant.

Diagnosis of the cause of tricuspid incompetence is important. When due to papillary muscle dysfunction it should be amenable to surgical treatment as is mitral incompetence (Fluck et al., 1966). If this patient had survived with persistent tricuspid incompetence the question of prosthetic valve replacement would have been seriously considered.

\section{Acknowledgments}

I would like to thank Dr M. W. McNicol for help in prepreparing this paper and Dr R. A. B. Drury for assistance with the autopsy findings.

\section{References}

Burch, G.E., De Pasquale, N.P. \& Phillips, J.H. (1963) Clinical manifestations of papillary muscle dysfunction. Arch. intern. Med. 112, 112.

Eisenberg, S. \& SUyemoto, J. (1964) Rupture of a papillary muscle of the tricuspid valve following acute myocardial infarction. Circulation, 30, 588.

Fluck, D.C., Taubman, J.O., Cleland, W.P. \& Mounsey, J.P.D. (1966) Acute mitral incompetence after acute myocardial infarction, with successful early treatment by mitral valve prosthesis. Lancet, ii, 1052.

HeIKKILÄ, J. (1967) Mitral incompetence complicating acute myocardial infarction. Brit. Heart J. 29, 162.

RafTery, E.B., OAKley, C.M. \& Goodwin, J.F. (1966) Acute subvalvar mitral incompetence. Lancet, ii, 360.

Roessle, R. \& Roulet, F. (1932) Mass und Zahl in Dexô Pathologie. Springer, Berlin.

Wartman, W.B. \& Hellerstein, H.K. (1948) The incidence of heart disease in 2,000 consecutive autopsies. Ann. intern. Med. 28, 41.

ZAus, E.A. \& KEARNS, W.M., Jr. (1952) Massive infarction of the right ventricle and atrium. Circulation, 6, 593.

\title{
Intrahepatic granulomatous arteriopathy
}

\author{
H. Fox \\ M.D., M.C.Path. \\ M. H. GleEsoN \\ M.B., Ch.B. \\ W. F. W. E. LoGAN \\ M.R.C.P. \\ Departments of Pathology and Cardiology, \\ University of Manchester and Manchester Royal Infirmary
}

\section{Summary}

The case history is detailed of a 55-year-old woman who was investigated for persistent pyrexia and anaemia. A liver biopsy specimen showed an unusual lesion of the small intrahepatic arteries. Many of these vessels showed circumferential replacement of their adventitial coat by a non-caseating granuloma whilst others showed localized granulomata focally interrupting the adventitial coat. The medial and intimal coats of the affected arteries were normal.
This was an intrahepatic granulomatous arteriopathy of unknown origin. The patient responded promptly and completely to steroid therapy.

\section{Introduction}

It is the purpose of this report to describe an unusual form of arteriopathy involving the intrahepatic vessels.

\section{Case report}

A woman, aged 55, was seen at Manchester 
Royal Infirmary in August 1965. She had a previous history of inguinal herniorraphy in 1951, hysterectomy for uterine fibroids in 1958, left tympanotomy for otosclerosis in 1962 and appendicectomy for acute appendicitis in 1964. She now gave a 2-month history of headaches, vomitting, nausea for sweet and fatty foods, anorexia, weight loss, fatigue and depression.

On examination, she was pale and sallow but, apart from some tenderness in the right hypochrondium, there was no other abnormality. Her haemoglobin was $9.8 \mathrm{~g} / 100 \mathrm{ml}$ and her white cell count was $11,400 / \mathrm{mm}^{3}$ with a normal differential count. A barium meal and a chest X-ray showed no abnormality.

The patient was treated with oral iron, but there was no symptomatic improvement, and when seen in September 1965 her haemoglobin had fallen to $6.9 \mathrm{~g} / 100 \mathrm{ml}$ and her ESR was $66 \mathrm{~mm}$ in $1 \mathrm{hr}$. She was therefore admitted to hospital for more detailed study.

Re-examination revealed no further abnormality, though there was still some tenderness in the right hypochrondium and it was thought by some observers that her liver was just palpable. She had a persistent pyrexia, her temperature usually being about $100^{\circ} \mathrm{F}$, but rising on occasions to $102-103^{\circ} \mathrm{F}$. Numerous investigations were performed, the majority of which gave negative results.

The positive findings were an iron-deficiency anaemia, a persistently elevated erythrocyte sedimentation rate and a leucocytosis. Liver function tests showed a serum albumen of $2.5 \mathrm{~g} / 100$ $\mathrm{ml}$, globulin $4.0 \mathrm{~g} / 100 \mathrm{ml}$, alkaline phosphatase 22 K.A. units $/ 100 \mathrm{ml}$, serum bilirubin 0.3 $\mathrm{mg} / 100 \mathrm{ml}$ and serum glutamic pyruvate transaminase $35 \mathrm{u} / 100 \mathrm{ml}$. The bromsulphalein retention was $33 \%$ at $45 \mathrm{~min}$ on one occasion and $23 \%$ when repeated. Multiple radiological studies failed to reveal any abnormality in the chest, gastrointestinal tract or urinary system, and tests for LE cells, antinuclear factor and rheumatoid factor were consistently negative. There was no serological evidence of syphilis. The routine investigations for a pyrexia of unknown origin proved unrewarding except for the finding of a postive brucellin skin test. However, on no occasion, either before or after this test, did the patient have a postive brucella antibody titre.

A diagnostic impasse having been reached, a laparotomy was performed in November 1965. At operation, all abdominal organs appeared normal and no masses were present. Biopsy specimens were taken from jejunum and liver.

\section{Biopsy findings}

The jejunal biopsy specimen showed no histological abnormality. The specimen of liver was a wedge of tissue measuring $1 \times 1 \times 0.5 \mathrm{~cm}$. Histologically, the hepatic parenchyma appeared normal ; there was no evidence of liver cell necrosis or fibrosis and no granulomatous lesions were present in the parenchyma. The hepatic sinuses were normal and there was no hyperplasia of the Kupfer cells. Most, but not all, of the medium-sized branches of the hepatic artery in the portal tracts of the specimen showed an unusual form of granulomatous inflammation of their adventitial coats. In many of the smaller of these arteries the adventitia was completely replaced by a non-caseating granuloma involving the full circumference of the arterial wall (Fig. 1), while in slightly larger vessels only a portion of the adventitial coat was replaced by a granuloma, the remaining portion of the vessel wall appearing normal. In larger arterial branches discrete granulomata were seen in the adventitia (Fig. 2), there producing sharply localized destruction of the adventitial fibro-muscular tissue, with the intervening portions of the adventitia

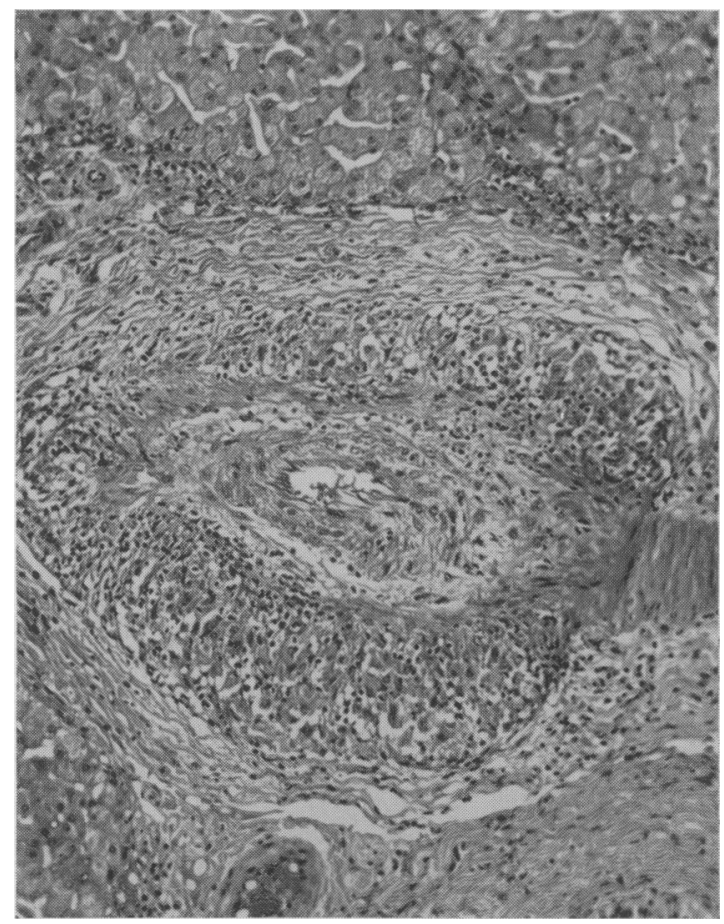

FIG. 1. The adventitial coat of a small intrahepatic artery is circumferentially replaced by a non-caseating granuloma which is confined to this layer of the arterial wall. $\mathrm{H} \& \mathrm{E}, \times 120$. 


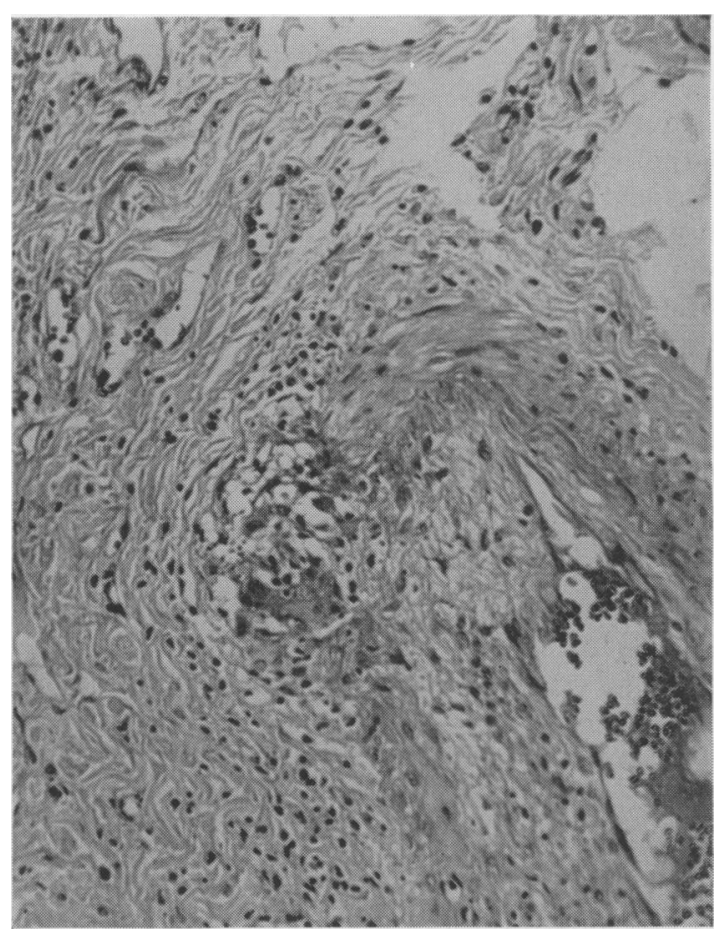

FIg. 2. A localized granuloma, which is focally interrupting the adventitia of an intrahepatic artery. $H \& E$, $\times 190$.

appearing completely normal. The granulomata consisted largely of epithelioid-cells with occasional Langhans' type giant-cells; foreign-body type giant-cells were not seen, while lymphocytes were sparse and there were no plasma cells. There was no caseation and no tubercle bacilli were seen after Ziel-Nielson staining. No fungi or bacteria were seen in sections stained with haematoxylin and eosin, PAS or Gram. The granulomata were strictly confined to the adventitial coat of the arteries and did not involve either the media of the vessel or the paravascular area. The media and intima were normal in all vessels: there was no evidence of fibrinoid necrosis, intimal thickening or cellular infiltration and no thrombi were seen. Elastic stain showed no evidence of destruction of elastic tissue in the vessel walls, the internal elastic laminae being intact and undamaged. The branches of the portal veins were normal as were the centrilobular veins. The interhepatic bile ducts were normal and there was no cellular infiltration of the portal tracts.

\section{Progress}

Although the hepatic biopsy demonstrated the presence of an unusual granulomatous condition affecting the arterioles it was impossible to make a definitive diagnosis. On clinical grounds the only investigation pointing to a possible aetiological agent was the positive brucellin skin test. The patient was therefore given $1 \mathrm{~g}$ of tetracycline daily for 4 months. This failed to produce any symptomatic improvement and at the end of this period the patient's ESR was still $44 \mathrm{~mm}$ in $1 \mathrm{hr}$ and her liver function tests were still abnormal. This treatment was therefore abandoned and the patient was started on prednisone, $30 \mathrm{mg}$ daily. This produced an immediate alleviation of her symptoms, and when seen 3 months later in August 1966 she was well; her ESR had fallen to $3 \mathrm{~mm}$ in $1 \mathrm{hr}$. She has continued on a gradually reducing dose of prednisone and has remained well.

\section{Discussion}

The clinical features of this patient were nonspecific and diagnosis was dependent on the findings in the liver biopsy specimen. These were difficult to interpret for the histological findings were not typical of any of the recognized arterial diseases. Thus, the absence of foreign-body giant-cells, medial damage, intimal thickening, elastic damage and fibrinoid necrosis was considered sufficient to exclude temporal arteritis, Takayasu's arteritis, hypersensitivity angiitis and the vascular lesions of polyarteritis nodosa, lupus erythematosus, Wegener's granulomatosis, systemic sclerosis, rheumatoid disease and dermatomyositis.

There was similarly no clinical or histological evidence that the patient was suffering from a generalized granulomatous disease in which the arteries were secondarily involved. The lesions in this case do indeed bear some resemblance to those occasionally seen in sarcoidosis (Erickson, Osom \& Stern, 1948; Meyer, Foley \& Campagna-Pinto, 1953). In the reported cases of sarcoid vasculitis, however, the granulomata have been basically parenchymal and vascular involvement has been an accidental result of enlargement of the granulomata, either arteries or veins being involved in an indiscriminate manner. In the present case in which granulomata were confined to the arterial walls and were totally absent from the hepatic parenchyma the diagnosis of sarcoidosis appeared unlikely.

The absence of caseation and of parenchymatous lesions also argued against tuberculosis and there were no findings to suggest syphilis, tularaemia, histoplasmosis or erythema nodosum. The patient had not been exposed to beryllium. Despite the positive brucellin test it was difficult 
to support the diagnosis of brucellosis for the agglutination test was persistently negative and the patient, though improving promptly with steroid therapy, failed to improve with prolonged administration of tetracycline.

It was therefore concluded that the patient was suffering from an intrahepatic granulomatous arteriopathy of unknown aetiology. Biopsies of other organs were not performed and hence it was not known whether this was an arteriopathy confined to the hepatic vessels or whether the liver biopsy allowed the opportunity to observe a local manifestation of a generalized disease. There were no clinical features to indicate specific involvement of any other organ but the persistent and unexplained anaemia indicates that the lesion, even if localized, was accompanied by systemic effects.

The prompt response to steroid treatment in this patient suggests, in the absence of any other obvious aetiological factors, a hypersensitivity reaction, though the arterial lesions did not resemble those described as typical of hypersensitivity states (Chure \& Strauss, 1951).

\section{Acknowledgments}

We are indebted to Professor A. C. P. Campbell for his advice and criticism; to Dr E. G. Wade for allowing us to quote the clinical details of this case and to Mr G. Humberstone for taking the photomicrographs.

\section{References}

Churg, J. \& Strauss, L. (1951) Allergic granulomatosis. allergic angiitis and periarteritis nodosa. Amer. J. Path, 27, 277.

Erickson, T.C., Odom, G. \& Stern, K. (1942) Boeck's disease (sarcoid) of the central nervous system. Arch. Neurol. Psychiat. 48, 613.

Meyer, J.S., Foley, J.M. \& Campagna-Pinto, D. (1953) Granulomatous angiitis of the meninges in sarcoidosis. Arch. Neurol. Psychiat. 69, 587.

\section{Sideropenic anaemia with reticulo-endothelial siderosis in a case of hypernephroma}

\author{
K. Chatterjee \\ M.R.C.P.(Lond.), M.R.C.P.(Edin.) \\ Medical First Assistant
}

\author{
G. E. MacLellaN
}

Medical Student

St George's Hospital, London, S.W.1

\section{Summary}

A case of sideropenic anaemia with reticuloendothelial siderosis is described. At the time of admission the anaemia was severe and the cause was not apparent. Extensive search had to be made to reveal the neoplasm, a hypernephroma.

\section{Introduction}

Of the various types of anaemias encountered in patients with neoplastic disease, sideropenic anaemia with reticulo-endothelial siderosis is the most interesting and puzzling. According to Cartwright (1966), it is usually mild in degree and not progressive in severity, but when the anaemia is moderately severe the causal neoplasm is almost always obvious. The case reported here presented with severe anaemia long before the underlying neoplasm could be detected.

\section{Case report}

The patient, a man aged 58 , a caterer by profession, was admitted with a 3 months' history of increasing tiredness, generalized weakness and shortness of breath on exertion. He had lost approximately 1 stone of weight in the 6 months preceding admission. He had never had indigestion and his appetite had always been good. The only relevant past history was that he had contracted syphilis about 30 years before.

On examination, he appeared very anaemic, but not jaundiced. The tongue, buccal mucous membranes, nails, palms and soles of the feet appeared pale but otherwise normal. There were no palpable glands or sternal tenderness. The skin and joints were normal. The liver was just palpable, one finger breadth below the right costal margin, smooth and not tender. All the features of a hyperkinetic circulation were present, with moderate tachycardia, slightly raised JVP, hyperdynamic cardiac impulse, flow murmurs in all cardiac areas, wide pulse-pressure, warm hands and digital pulsation. The only other $a b$ normal physical finding was the presence of Argyll Robertson pupils-evidence of neurosyphilis. Capillary fragility test, rectal examination and proctoscopy were normal. 